\title{
Proprioceptive modulation of somatosensory evoked potentials during active or passive finger movements in man
}

\author{
G ABBRUzzeSE, S RATTO, E FAVALE, M ABBRUZzESE \\ From the Department of Neurology, University of Genoa, Genoa, Italy
}

SUMMARY The effects of active and passive finger movements on somatosensory potentials evoked by stimulation of the median nerve at the wrist or of finger I were investigated in 15 healthy volunteers. As compared to the resting condition, both active and passive movements of the stimulated hand fingers induced a marked reduction in the amplitude of the primary cerebral response (N20P25 complex) as well as of the N17 SEP component, which is supposed to reflect the activity of the thalamo-cortical radiation. The following cerebral SEP components, within $100 \mathrm{~ms}$ after the stimulus, were also depressed during motor activity. Neither N11 nor N13 components of the cervical response, reflecting the activation of dorsal columns and dorsal column nuclei respectively, were modified. The SEP changes induced by active or passive movements were absent after ischaemic block of large group I afferent fibres from the hand, thus suggesting the relevance of the feedback generated by such peripheral afferents during movement. The results indicate that the activation of peripheral receptors (probably muscle spindle endings) during both active and passive finger movement would induce a gating effect at both cortical and subcortical (thalamic) level, which might modulate selectively the different sensory inputs to the cortex.

Since Giblin ${ }^{1}$ first observed that the amplitude of the human somatosensory evoked potential (SEP) was greatly reduced by finger movements or by natural stimuli repeatedly applied to the fingers of the stimulated hand, several reports have been centred on SEP modifications induced by either active or passive movements. Broughton et $a l^{2}$ described a decrease in amplitude of the late SEP components during active fist clenching. Coquery et $a^{3}$ observed a marked reduction or even a suppression of all the components of the somesthesic response evoked during either active or passive movements of the fingers. According to Lee and White, ${ }^{4}$ the late SEP components increased both in amplitude and in latency during active voluntary movement, but not during passive movement or sustained isometric contraction, while the earlier SEP components, occurring between 50 and $100 \mathrm{~ms}$, were slightly decreased in amplitude. Other authors ${ }^{5}$ described a drastic decrease in amplitude of cortical potentials evoked in the postcentral area during self placed

Address for reprint requests: Giovanni Abbruzzese MD, Clinica Neurologica, Via De Toni 5, I 16132 Genova, Italy'

Accepted 1 July 1981 hand displacements, while, according to Craggs et al, ${ }^{6}$ the N55 component of the SEP was markedly reduced by both active and passive thumb flexions, the primary response being relatively unaffected.

Owing to some discrepancies in such observations varying hypotheses regarding the mechanisms underlying SEP changes induced by active or passive movements of the fingers, have been proposed. It is still unclear whether such a mechanism be "afferent" (that is activation of peripheral afferents) ${ }^{6}$ or "efferent" (that is the effect of descending pyramidal and extrapyramidal influences) ${ }^{4}$ in origin, or both. ${ }^{3}$

A suitable analysis of "precortical" SEP components has not so far been carried out, at least in man, so that it is impossible to state exactly whether the interaction responsible for the SEP changes takes place exclusively at the cortical level ${ }^{2} 6$ or even along the lemniscal pathway. ${ }^{3}$ The aim of the present study was to investigate further the SEP modifications induced by various kinds of motor activity, and particularly by either active or passive finger movements, trying to determine (a) the anatomical level or levels, (b) the relative specificity, and (c) the actual nature of the interaction responsible 
for such changes. For this purpose, a specific analysis was performed of the behaviour of the SEP components which are supposed to reflect the activity of the dorsal columns (N11) and dorsal column nuclei $(\mathrm{N} 13)^{78}$ and of the thalamo-cortical radiation (N17). ${ }^{9}$

Preliminary results have been presented to the meeting of the Società Italiana di Elettroencefalografia e Neurofisiologia (Capri, May 29-31, 1980).

\section{Material and methods}

SEPs were recorded in 15 healthy volunteers (13 males and 2 females), recruited from internal residents and ranging in age from 24 to 40 years (mean age: $29 \cdot 4$ ). Each subject was not examined with the full experimental procedure.

\section{Stimulation and recording techniques}

Stimulating bipolar surface electrodes were placed over the median nerve trunk, just proximal to the wrist, or strapped around the thumb. Stimuli consisted of square wave pulses of $0.2 \mathrm{~ms}$ duration, generated by a DISA $14 \mathrm{E} 01$ Ministim stimulator at a rate of $1 \mathrm{~Hz}$. Two intensities were used for stimulating the median nerve (just below motor threshold and two times motor threshold), while at finger I the intensity of stimulation was always kept above the sensory threshold but below the pain threshold. Monopolar recordings of both cerebral and cervical responses were obtained from the active electrode, placed respectively over the stimulated hand projection area and between the second and the third cervical spines, with the reference electrode on the upper forehead on the midline. ${ }^{10}$ The neurogram of the median nerve was concurrently recorded at the Erb's point. ${ }^{11}$ Monopolar recordings were performed by means of fine subcutaneous needles, with an electrode impedance of 1,000-2,000 ohms. The responses were amplified by DISA 14 C 12 EMG amplifiers (bandwidth: $1.6 \mathrm{~Hz}-10$ $\mathrm{KHz},-3 \mathrm{~dB}$ ) and recorded on a magnetic tape (Philips Analog 7). 128 or 256 responses were usually summated (DISA 14 G 01 Digital Averager) and displayed on an X-Y plotter (Philips PM 8125). An analysis time of $50 \mathrm{~ms}$ was used for the cervical response, while both 50 and $200 \mathrm{~ms}$ were used for the cerebral response.

\section{Experimental procedures}

Recordings were performed while the subjects were kept relaxed on a couch in a quiet room, with the supinated hand lying on the couch seat and the forearm immobilised in a wooden frame so that movement was possible only at the interphalangeal and metacarpo-phalangeal joints. The arm was gently warmed by an infrared lamp throughout the experiments to ensure a skin temperature of $36-38^{\circ} \mathrm{C}$ corresponding to $35-37^{\circ} \mathrm{C}$ along the median nerve trunk. Separate recordings of SEPs were obtained (a) in the resting condition, (b) during active voluntary movement, and (c) during passive movement. The subjects were instructed to perform, under both isometric (that is fixed joint) and isotonic (that is joint free to move) conditions, repeated ballistic movements of flexionextension of the thumb (or of the other fingers) at a rate of about $1 \mathrm{~Hz}$, maintaining a constant speed in a range of approximately $90^{\circ}$. Passive movements with the same characteristics were performed by the experimenter. The beginning of movement did not coincide with the electrical shocks, the latter generally falling during the flexion phase. It was carefully checked that movement did not shift the stimulating electrodes and that the stimulating current remained constant throughout each experiment. The effect of a sustained tonic contraction of the fingers (fist clenching) and of either passive or voluntary movements of the contralateral hand or of the ipsilateral foot was investigated as well. SEPs were also recorded during gentle stroking (with a gauze) of the finger skin or during a conditioning high frequency $(100 \mathrm{~Hz})$ stimulation of the thumb, with a stimulus strength (60 up to $100 \mathrm{~V})$ causing intense cutaneous paresthesias. Finally, control recordings were performed in the identical experimental conditions, during both active and passive movement, with the electrical stimulation turned off.

In addition, in four subjects the somesthesic response was evoked by stimulation of the neuro-vascular trunk at the middle third of the arm and the SEP modifications induced by finger movements were tested before and after ischaemic block of large diameter afferent fibres from the hand, obtained by placing a sphygmomanometer cuff, inflated above systolic arterial pressure, around the arm below the site of stimulation.

\section{Data analysis}

Under each experimental condition, both peak latency and amplitude (with reference to the base line) of the median nerve neurogram and of the following SEP components were measured: (1) the N11 and N13 components, as well as the following large positive deflection, of the cervical response, (2) the N17, N20 and P25 components of the cerebral response. The amplitude of the subsequent cerebral SEP components, occurring within $200 \mathrm{~ms}$ after the stimulus (see Results), was measured from the preceding peak of opposite polarity. Data were statistically evaluated by means of the analysis of variance and the Newman-Keuls test for individual comparisons of means. ${ }^{12}$

\section{Results}

EFFECT OF MOVEMENT ON THE MEDIAN

NERVE NEUROGRAM

Both latency and amplitude of the median nerve neurogram recorded at Erb's point were unchanged during passive movement, active voluntary movement (see fig $1 \mathrm{~A}$ ) or sustained tonic contraction of the fingers of the stimulated hand.

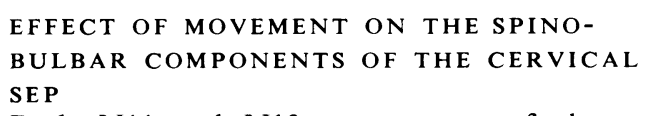

Both N11 and N13 components of the cervical response evoked by stimulation of the median nerve 


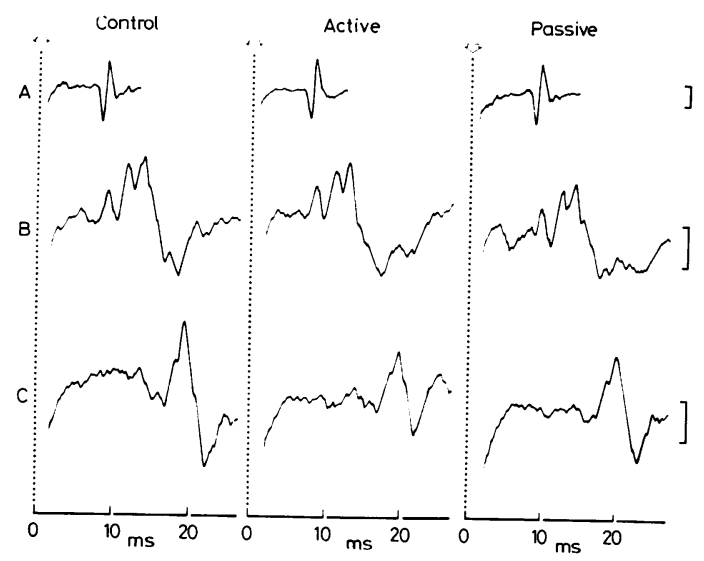

Fig 1 Concurrent recordings of: $(A)$ median nerve neurogram at the Erb's point, $(B)$ cervical SEP and $(C)$ cerebral SEP, upon stimulation of the median nerve at the wrist (intensity of stimulation: 2 times motor threshold), during resting condition, active finger movement and passive finger movement. The amplitude of N17, N2O and P25 components of the cerebral SEP is markedly reduced during both active and passive finger movements, while no significant modification of the N11 and N13 components of the cervical SEP can be observed. The median nerve neurogram is unchanged during motor activity. 128 responses were summated. Calibration: $1 \mu \mathrm{V}$. In this and in the following illustrations, positivity is downwards.

at the wrist did not show latency shifts (table 1), during either active or passive finger movements. The mean amplitude of the N11 and N13 cervical SEP components did not show changes associated with either active or passive finger movements (fig $1 \mathrm{~B}$ ). Only a slight but statistically insignificant amplitude reduction could be observed, particularly in the case of the N13 component (table 2). On the contrary, the mean amplitude of the large positive deflection following N13 was significantly $(p<0.01)$ reduced during both types of movement (see fig $1 \mathrm{~B}$ ). (It should be pointed out that such deflection is supposed to reflect largely the activity of cortical and subcortical structures. ${ }^{13}{ }^{14}$ )

\section{EFFECTS OF MOVEMENT ON THE THALAMO- CORTICAL COMPONENTS OF THE CEREBRAL SEP}

A. Compared with the resting condition, both active and passive movements markedly reduced the N17, N20 and P25 SEP components upon median nerve stimulation (fig $1 \mathrm{C}$ ), their mean latencies showing only minimal shifts statistically insignificant (table 1). The reduction in amplitude was statistically significant (table 2 ), independently of
Table 1 Mean latency ( $m s$ ) changes of SEP components during active and passive finger movements

\begin{tabular}{lllll}
\hline & Control & Active & Passive & F-test \\
\hline N11 & $11.03 \pm 0.84$ & $11.05 \pm 0.73$ & $11.05 \pm 0.74$ & $0.14 \mathrm{~ns}$ \\
N13 & $12.79 \pm 0.76$ & $12.71 \pm 0.68$ & $12.80 \pm 0.70$ & $0.13 \mathrm{~ns}$ \\
N17 & $17.42 \pm 0.80$ & $17.54 \pm 0.79$ & $17.48 \pm 0.87$ & $2.47 \mathrm{~ns}$ \\
N20 & $18.82 \pm 0.63$ & $18.91 \pm 0.73$ & $18.95 \pm 0.71$ & $1.24 \mathrm{~ns}$ \\
P25 & $21.94 \pm 1.05$ & $21.90 \pm 1.10$ & $21.96 \pm 1.07$ & $0.27 \mathrm{~ns}$ \\
\hline
\end{tabular}

Mean $\pm S D(n=10) n s=$ not significant.

Table 2 Mean amplitude ( $\mu V$ ) changes of SEP components during active and passive finger movements

\begin{tabular}{lllll}
\hline & Control & Active & Passive & F-test \\
\hline N11 & $1.56 \pm 0.58$ & $\begin{array}{l}1.47 \pm 0.56 \\
(6 \%)\end{array}$ & $\begin{array}{l}1.55 \pm 0.43 \\
(1 \%)\end{array}$ & $0.97 \mathrm{~ns}$ \\
N13 & $1.67 \pm 0.61$ & $\begin{array}{l}1.37 \pm 0.70 \\
(18 \%)\end{array}$ & $\begin{array}{l}1.43 \pm 0.42 \\
(14 \%)\end{array}$ & $2.79 \mathrm{~ns}$ \\
N17 & $0.96 \pm 0.24$ & $\begin{array}{l}0.59 \pm 0.22 \\
(39 \%)^{*}\end{array}$ & $\begin{array}{l}0.62 \pm 0.22 \\
(35 \%)^{*}\end{array}$ & $25.98 *$ \\
N20 & $1.87 \pm 0.37$ & $\begin{array}{l}1.06 \pm 0.39 \\
(43 \%)^{*}\end{array}$ & $\begin{array}{l}1.02 \pm 0.29 \\
(45 \%)^{*}\end{array}$ & $59.96 *$ \\
P25 & $1.69 \pm 0.62$ & $\begin{array}{l}0.94 \pm 0.52 \\
(46 \%)^{*}\end{array}$ & $\begin{array}{l}1.09 \pm 0.52 \\
(36 \%)^{*}\end{array}$ & $50.74 *$ \\
& & &
\end{tabular}

Mean $\pm S D(n=10) n s=$ not significant $* p<0.01$

Between brackets the mean percentage of amplitude decrease during active and passive movements, as compared to the resting condition, with the relative significance of the Newman-Keuls test.

the intensity of electrical stimulation (below or two times motor threshold), of the involved segments 8 (the thumb or the other fingers) or of the type of contraction. In fact, the amplitude reduction was slightly, but not statistically significantly, larger under isometric conditions than under isotonic conditions. Such changes in amplitude affected all the components to the same degree, no differences being observed between the effect of active and passive movements. The N17, N20 and P25 components of the response evoked by finger I stimulation showed exactly the same trend (fig 2).

Both active and passive finger movements of the hand contralateral to the side being stimulated did not produce any change of either latency or amplitude of the SEP components under investigation; likewise, no effect could be noticed during either passive or active plantar flexion of the ipsilateral foot. Only minor, insignificant, amplitude changes of N17, N20 and P25 SEP components were associated with sustained fist clenching.

B. As is well known, the SEP components following the primary response (that is the N20-P25 complex), are characterised by a high variability, ${ }^{15}$ even the most consistent components showing large fluctuations both in amplitude and in latency. In our subjects, their usual shape consisted (see fig 3 , upper trace) of a large triphasic positive-negative-positive 


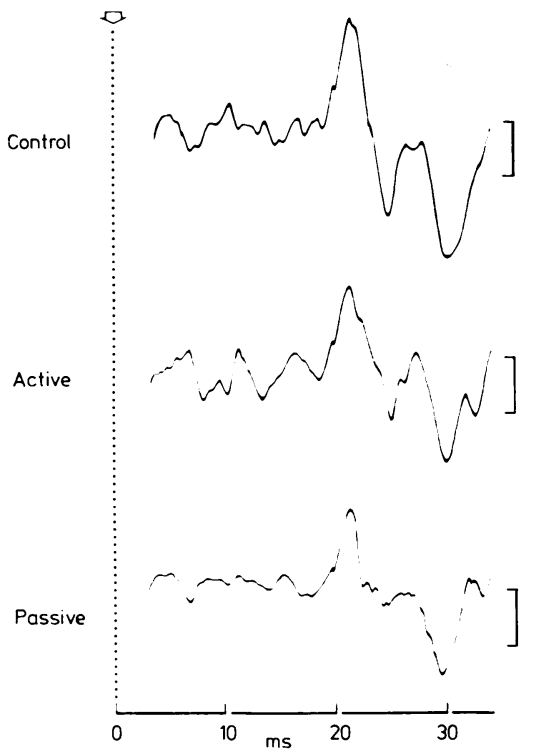

Fig 2 Cerebral somatosensory response evoked by stimulation of the finger I during resting condition (upper trace), active finger movement (middle trace) and passive finger movement (lower trace). The amplitude of the N17, N20, and P25 components is reduced during both active and passive movements. 256 responses were summated. Calibration: $0.5 \mu \mathrm{V}$.

complex (mean latencies: $34 \cdot 3 \pm 2 \cdot 8,44 \cdot 5 \pm 2 \cdot 7$ and $58.6 \pm 3.4 \mathrm{~ms}$ ), followed by a second more variable triphasic complex with a negative peak occurring between 64 and $75 \mathrm{~ms}$ (mean latency: $69.3 \pm 5 \cdot 3 \mathrm{~ms}$ ). Such morphology corresponds to the classic descriptions. ${ }^{15} 16$

While the mean latencies of the two large triphasic complexes were not substantially modified by either active or passive finger movements, their mean amplitude was markedly reduced (see fig 3), particularly in the first complex, this segment of the evoked response being sometimes almost completely suppressed during motor activity. At times further late waves, slower and more irregular, could be observed with negative peaks occurring between 100 and 140 ms. Their amplitude was not substantially modified during movement. The events occurring after the first $200 \mathrm{~ms}$ were not investigated.

EFFECT OF OTHER STIMULI

In a few cases light stroking of the skin of the fingers caused a small amplitude reduction, mainly affecting the P25 component. The relative discrepancy between this result and that obtained in similar experiments by Giblin ${ }^{1}$ could depend on

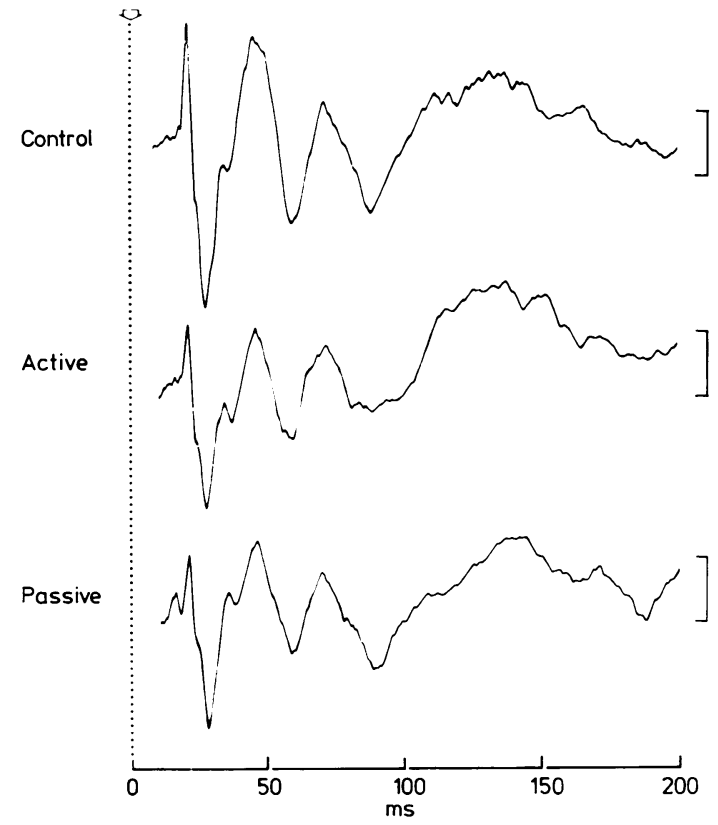

Fig 3 Cerebral somatosensory response evoked by stimulation of the median nerve at the wrist (intensity of stimulation: 2 times motor threshold), during resting condition (upper trace), active finger movement (middle trace) and passive finger movement (lower trace). The SEP components following the primary response are considerably depressed in amplitude during both active and passive movements. 128 responses were summated. Calibration: $1 \mu \mathrm{V}$.

differences in the nature and/or the intensity of the applied stimuli. Both cervical and cerebral SEPs recorded during a conditioning electrical stimulation of the thumb sometimes showed a decrease in amplitude during the first trials, before the subjects became adapted to the conditioning stimuli. Such changes, when present, were associated with a consistent decrease in amplitude of the median nerve neurogram (see fig 4), probably due to a peripheral occlusion phenomenon.

Finally, it should be pointed out that under our experimental conditions neither active nor passive movements were apparently related to a clear cut cerebral response: in particular, when the electrical stimulation was turned off, no detectable event could be recorded during repeated finger flexions.

\section{EFFECT OF ISCHAEMIA ON THE SEP} CHANGES INDUCED BY MOVEMENT

The somesthesic response evoked by stimulation of the neurovascular trunk at the middle third of the arm was characterised by the same waveform as the 

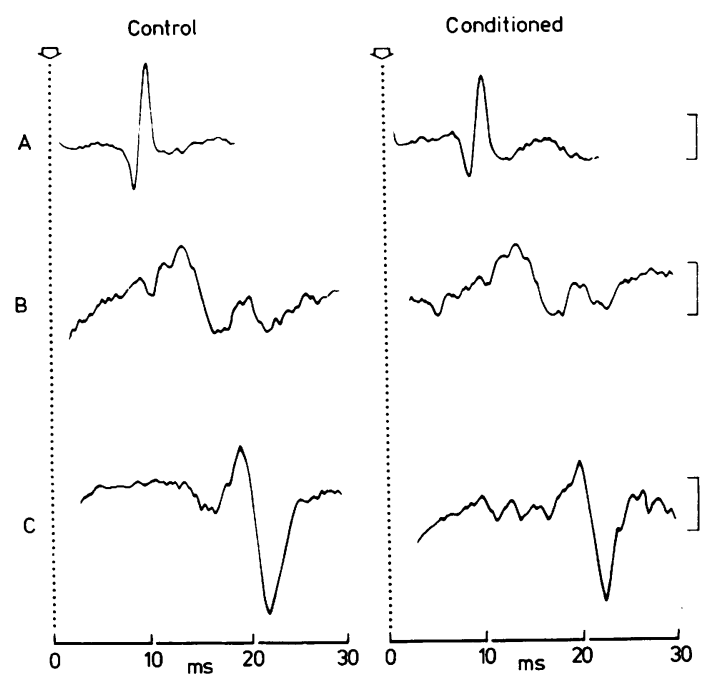

Fig 4 Concurrent recordings of : $(A)$ median nerve neurogram at the Erb's point, $(B)$ cervical SEP and (C) cerebral SEP, upon stimulation of the median nerve at the wrist (intensity of stimulation: 2 times motor threshold), during control (left) and conditioning cutaneous stimulation $(100 \mathrm{~Hz}, 80 \mathrm{~V})$ of the thumb (right). The conditioning cutaneous stimulation induces consistent amplitude changes of both cervical and cerebral SEP as well as of the median nerve neurogram. 128 responses were summated. Calibration: $1 \mu \mathrm{V}$.
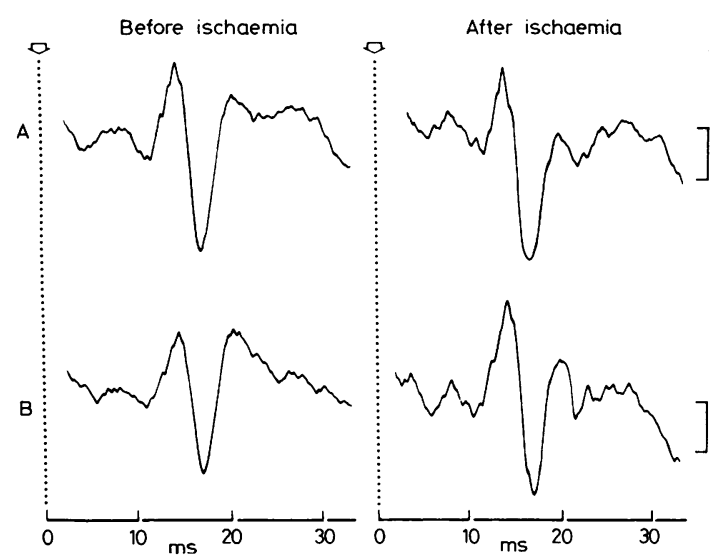

Fig 5 Cerebral somatosensory response evoked by stimulation of the neuro-vascular trunk at the middle third of the arm, during $(A)$ resting condition and (B) active finger movement, before (left) and after (right) ischaemic block. The N17, N20 and P25 components are reduced in amplitude by active finger movement before ischaemic block, remaining unchanged after ischaemic block. 68 responses were summated. Calibration: $1 \mu \mathrm{V}$. response evoked by stimulation of the median nerve at the wrist and it was modified by either active or passive finger movements in the same way (fig 5, left). After 15-20 minutes of ischaemia the SEP evoked by stimulation at the wrist was almost abolished, owing to the block of large group 1 afferent fibres, the SEP evoked by stimulation at the middle third of the arm being normal. At this time, a complete distal anaesthesia had developed but the subjects were still able to move their hand actively, probably because of the greater resistance to ischaemia of motor fibres than sensory fibres. ${ }^{17} 18$ If active or passive finger movements were perfomed, however, no amplitude modification of SEP components could be observed (fig 5 , right).

\section{Discussion}

We have shown in this study that both thalamic and cortical components of the cerebral SEP upon median nerve or finger I stimulation present a marked decrease in amplitude during either active or passive finger movement of the stimulated hand. In contrast, under the same conditions, both the median nerve neurogram and the spino-bulbar components of the cervical SEP failed to show significant changes.

The substantial invariability of the median nerve neurogram during motor activity, in addition to ruling out the occurrence of inadvertent shifts of the stimulating electrodes, suggests that a "peripheral occlusion" phenomenon is not likely to account for the reduction in amplitude of the cerebral SEP components. Moreover, such a mechanism should have caused consistent changes of both cervical and cerebral SEP components, as shown by the effect of high frequency cutaneous stimulation, when the latter brought about a decrease in amplitude of the median nerve neurogram (see fig 4).

Both the N11 and N13 components of the cervical SEP, which are supposed to reflect the activity of the dorsal columns and of the dorsal column nuclei respectively, 7819 were not modified by the different types of movement. It is well known that the responses evoked in the cuneate nucleus or in the medial lemniscus of the cat are depressed during voluntary movement ${ }^{2021}$ and that a large convergence of peripheral afferents has been shown in the dorsal columns cells. ${ }^{22}{ }^{23}$ It does not seem, however, that the first station of the lemniscal pathway is the main seat of the interaction responsible for the observed cerebral SEP changes, at least on the basis of our results in man.

On the other hand, both active and passive movements reduced the amplitude of N20-P25 SEP components, which are widely accepted to 
represent the first cortical events, ${ }^{24}$ as well as of the N17 component, which is regarded as the far field reflection of the thalamo-cortical radiation activity. ${ }^{9}$ Therefore, at variance with previous observations, ${ }^{4} 6$ it can be maintained that the mechanisms responsible for the SEP changes are acting not only at the cortical level, but also along the ascending lemniscal pathway, at least at the thalamic level.

As to the mechanisms responsible for the SEP changes observed during motor activity, Lee and White $^{4}$ suggested that the alterations of SEPs may reflect "a central nervous system interaction between afferent and efferent systems", since SEPs were affected only by voluntary movements, whereas no consistent SEP modification was observed when the hand was moved passively. On the contrary, we could demonstrate, in agreement with Coquery et $a l^{3}$ and Craggs et al, ${ }^{6}$ that both active and passive finger movements reduced SEPs, approximately to the same degree. Though there is considerable evidence that pyramidal tract fibres may modulate afferent transmission of sensory information, ${ }^{21}$ this did not appear to be the case in our study. We could demonstrate that the cerebral response evoked by stimulation of the neuro-vascular trunk at the middle third of the arm was not altered during ischaemia of the actively moving hand, when the large group I afferents were blocked. Therefore, it can be assumed that the SEP modifications induced by active movements are likely to depend largely on the activation of peripheral afferents, rather than on an interaction between efferent and afferent systems occurring during active movement.

It is well known that several receptor populations can be excited during movement. Nevertheless, a tentative identification of the receptors mainly responsible for the SEP changes induced by motor activity can be made on the basis of previous contributions as well as of the present results. The possible role of joint receptors does not seem to be particularly relevant, since anaesthesia of the thumb joint does not reduce the effect of active and passive thumb flexions on the SEP $;^{6}$ moreover, joint receptors are certainly not strongly activated during isometric contractions. Similarly, cutaneous receptors, which may respond to voluntary finger movements, ${ }^{25}$ are not likely to be preferentially involved, since skin anaesthesia ${ }^{6}$ or cooling ${ }^{11}$ do not reduce the effect of movement and vibration respectively on the SEPs. In addition, we showed that neither mild stroking of the skin nor high frequency cutaneous stimulation of the thumb induced evident SEP changes, unless the latter were associated with a decrease in amplitude of the median nerve neurogram.

It is well known that Golgi receptors are relatively insensitive to passive stretch, ${ }^{26} 27$ while muscle spindle endings show a high dynamic sensitivity to stretch. ${ }^{28} 29$ This may suggest a possible causal relationship between the activation of muscle afferents and the present findings, particularly because similar changes of SEPs were recently observed $^{11}$ during mechanical vibration of hand muscles. Moreover, this hypothesis is indirectly supported by several lines of evidence showing that muscle afferents do project to the cerebral cortex. ${ }^{30-33}$

Summing up, although a possible contribution from other receptors cannot be completely ruled out, the modifications of SEPs observed during movement are likely to depend mainly on the activation of muscle spindle endings. In fact, the modifications of SEPs seemed to be strictly related to either passive stretch or voluntary contraction, when the muscle spindle discharge is drastically accelerated under both isometric and isotonic conditions, ${ }^{29} 3435$ even in spite of the mechanical unloading effect which is more evident when the contracting muscle is allowed to shorten. ${ }^{35}$ On the contrary, no SEP modification was observed during sustained fist clenching, when several muscles may be coactivated, thus inducing a stronger unloading effect. ${ }^{29}$ The possible role of muscle stretch receptors was suggested also by Craggs et $a l,{ }^{6}$ who pointed out the relationship existing between the degree of suppression and the increasing velocity of movement. As a matter of fact, the relationship between SEP changes and torque of contraction or speed and acceleration of movement should be further investigated, since the SEP modifications may be related to specific parameters of the movement.

Coquery et $a l^{3}$ observed SEP changes associated with movement of the feet or of the fingers contralaterally to the stimulation side. However, in agreement with Lee and White, ${ }^{4}$ in our study the effect of movement was quite specific, since the cerebral response was not significantly modified when the ipsilateral foot or the contralateral fingers were moved, thus indicating that only stretching of the receptor-bearing muscles close to the stimulated area was effective. We have observed also that the cerebral response evoked by stimulation of the lower limb (tibial nerve) was markedly reduced during movement of the ipsilateral foot, being on the contrary unaffected by ipsilateral hand movement (unpublished observation).

Our findings, therefore, imply that the activation of muscle stretch receptor afferents, during both active and passive finger movements, might be responsible for an interaction at subcortical level leading to the alteration of SEPs. Such a mechanism could be interpreted as a movement related "gating" effect, ${ }^{6}$ which might modulate selectively the different 
sensory inputs to the cortex. In particular, this "gate" may be at the thalamic level, as suggested by the reduction in amplitude of the N17 SEP component, constantly observed during both active and passive movements.

A possible cortical contribution to SEP changes should be considered as well, though a reduction of cerebral SEPs due to simple overlapping with other cortical events can be ruled out, since the concomitant occurrence of surface potentials related to the movement could be excluded, at least under our experimental conditions. In any case, there is little doubt that SEP changes occurring during movements may result, at least in part, from mechanisms operating even at the cortical level. The reduction in amplitude of the cerebral SEP might be due, in fact, to an occlusion of cortical neurons by a continuous bombardment from muscle afferents. In this regard Goldring and Ratcheson ${ }^{31}$ found, in the hand area of the human motor cortex, single units responding to both active and passive movements of the contralateral hand. It should be pointed out, however, that according to these authors, cells responding to passive or active movements were not influenced by cutaneous stimuli. On the contrary, Soso and Fetz ${ }^{36}$ identified in the monkey postcentral cortex, cells responding to cutaneous stimulation as well as to active and passive joint movements. The data so far available are too scanty to allow any definite conclusion about the cortical occlusion hypothesis, at least in man.

Finally, the behaviour of the late SEP components should be considered, since the latter might be generated ${ }^{37-39}$ by impulses transmitted through the medial thalamic pathways, that is the so-called "non-specific" afferent system, so that it could be argued that muscle afferents are able to interact with both "specific" and "non specific" parts of the afferent system. According to the majority of authors, ${ }^{40} 41$ however, both early and late SEP components are mediated by the dorsal columnmedial lemniscus system. The same mechanisms, therefore, which are responsible for the reduction of the primary response can explain also the suppression of the late SEP components observed during active and passive movements.

In conclusion, even if the functional role of the cortical projections from muscle afferents is not fully understood, such a proprioceptive feedback is certainly relevant in motor control, since signals from muscle spindle afferents, being involved in long loop regulation ${ }^{42} 43$ or "servo" correction ${ }^{44}$ of ballistic movements, may interact with a motor program.45 46 Moreover, the relevance of a "gating" action, related to movement, and exerted on the sensory pathways through their course to the cortex, should be considered as well. In agreement with previous observations, ${ }^{35}$ the subjects in our study also reported a decrease in the intensity of the sensation induced by the electrical shocks only during movement of the stimulated hand but not during movement of distant segments. In addition, a reduction of cutaneous sensibility has been shown during ballistic preprogrammed movements. ${ }^{47}$

A "gating" mechanism, therefore, could affect the input to the sensory cortex, acting as a selector of sensory information upon which prompt action is necessary. ${ }^{5}$

\section{References}

${ }^{1}$ Giblin DR. Somatosensory evoked potentials in healthy subjects and in patients with lesions of the nervous system. Ann NY Acad Sci 1964;112:93-142.

${ }^{2}$ Broughton R, Regis H, Gastaut H. Modifications of somaesthesic evoked potentials during bursts of $\mathrm{mu}$ rhythm and during fist clenching. Electroencephalogr Clin Neurophysiol 1965;18:720.

${ }^{3}$ Coquery J-M, Coulmance M, Leron M-C. Modifications des potentiels évoqués corticaux somesthésiques durant des mouvements actifs et passifs chez l'homme. Electroencephalogr Clin Neurophysiol 1972;33:269-76.

${ }^{4}$ Lee RG, White DG. Modification of the human somatosensory evoked response during voluntary movement. Electroencephalogr Clin Neurophysiol 1974; 36:53-62.

${ }^{5}$ Papakostopoulos D, Cooper R, Crow HJ. Inhibition of cortical evoked potentials and sensation by selfinitiated movement in man. Nature 1975;258: 321-4.

${ }^{6}$ Craggs MD, Rothwell JC, Rushton DN. Gating of somatosensory evoked potentials by active and passive movements in man. J Physiol (London) 1979;295:96-7 P.

${ }^{7}$ Jones SJ. Short latency potentials recorded from the neck and the scalp following median nerve stimulation in man. Electroencephalogr Clin Neurophysiol 1977;43:855-63.

${ }^{8}$ Abbruzzese M, Favale E, Ivaldi M, Leandri M, Ratto S. Nuove acquisizioni sulla risposta cervicale somestesica. Riv Ital Elettroencef Neurofisiol 1979; 2:599-603.

${ }^{9}$ Abbruzzese M, Favale E, Leandri M, Ratto S. New subcortical components of the cerebral somatosensory evoked potentials in man. Acta Neurol Scand 1978;58:325-32.

${ }_{10}$ Abbruzzese M, Favale E, Leandri M, Ratto S. Spinal components of the cerebral somatosensory evoked response in normal man: the "S wave". Acta Neurol Scand 1978;58:213-20.

${ }^{11}$ Abbruzzese G, Abbruzzese M, Favale E, Ivaldi M, Leandri $M$, Ratto $S$. The effect of hand muscle vibration on the somatosensory evoked porential in man: an interaction between lemniscal and spinocerebellar inputs? J Neurol Neurosurg Psychiatry $1980 ; 43: 433-7$. 
${ }^{12}$ Winer BJ. Statistical principles in experimental design. New York: McGraw-Hill, 1971.

${ }^{13}$ Abbruzzese M, Favale E, Leandri M, Ratto S. Ricerche sulle componenti encefaliche del potenziale spinale evocato da stimolazione del nervo mediano nell'uomo. Boll Soc Ital Biol Sper 1978;54:1925-30.

${ }^{14}$ Shimoji K, Shimizu H, Maruyama Y. Origin of the somatosensory responses recorded from the cervical skin surface. J Neurosurg 1978;48:980-4.

${ }^{15}$ Halliday AM. Somatosensory evoked responses. In: Remond A, ed. Handbook of EEG and Clinical Neurophysiology. Amsterdam: Elsevier, 1975;vol:8,60-7.

${ }^{16}$ Halliday AM. Clinical applications of evoked potentials. In: Matthews WB, Glaser GH, eds. Recent advances in clinical neurology. Edinburgh: Churchill Livingstone, 1978:47-73.

17 Magladery JW, McDougal DB, Stoll J. Electrophysiological studies of nerve and reflex activity in normal man. II. The effects of peripheral ischaemia. Bull Johns Hopk Hosp 1950;86:291-312.

${ }^{18}$ Bussel B, Morin C, Pierrot-Deseilligny E. Mechanism of monosynaptic reflex reinforcement during Jendrassik manoeuvre in man. $J$ Neurol Neurosurg Psychiatry 1978;41:40-4.

${ }^{19}$ Leandri M, Favale E, Ratto S, Abbruzzese M. Conducted and segmental components of the somatosensory cervical response. J Neurol Neurosurg Psychiatry 1981; in press.

${ }^{20}$ Ghez C, Pisa M. Inhibition of afferent transmission in cuneate nucleus during voluntary movement in the cat. Brain Res 1972;40:145-51.

${ }^{21}$ Coulter JD. Sensory transmission through lemniscal pathway during voluntary movement in the cat. J Neurophysiol 1974;37:831-45.

2.2 Millar J. Convergence of joint, cutaneous and muscle afferents onto cuneate neurones in the cat. Brain Res $1979 ; 175: 347-50$.

23 Jankowska E, Rastad J, Zarzecki P. Segmental and supraspinal input to cells of origin of non-primary fibres in the feline dorsal columns. J Physiol (London) 1979;290:185-200.

${ }^{24}$ Desmedt JE. Somatosensory evoked potentials in man. In: Remond A, ed. Handbook of EEG and Clinical Neurophysiology. Amsterdam: Elsevier, 1971;vol. 9:55-82.

${ }^{25}$ Hulliger M, Nordh E, Thelin A-E, Vallbo AB. The response of afferent fibres from the glabrous skin of the hand during voluntary finger movements in man. J Physiol (London) 1979;291:233-49.

${ }^{26}$ Burg D, Szumski AJ, Struppler A, Velho F. Afferent and efferent activation of human muscle receptors involved in reflex and voluntary contractions. Exper Neurol 1973;41:754-68.

${ }^{27}$ Houk J, Henneman E. Responses of Golgi tendon organs to active contractions of the soleus muscle in the cat. $J$ Neurophysiol $1967 ; 30: 466-81$.

28 Matthews PBC. Mammalian Muscle Receptors and their Central Actions. London: Arnold, 1972.

${ }^{29}$ Vallbo AB, Hagbarth K-E, Torebjork HE, Wallin BG. Somatosensory, proprioceptive and sympathetic activity in human peripheral nerves. Physiol Rev 1979;59:919-57.
${ }^{30}$ Phillips CG, Powell TPS, Wiesendanger M. Projection from low-threshold muscle afferents of hand and forearm to area 3a of baboon's cortex. J Physiol (London) $1971 ; 217: 419-45$.

${ }^{31}$ Goldring S, Ratcheson R. Human motor cortex: sensory input data from single neuron recordings. Science 1972;175:1493-5.

${ }^{32}$ Shibasaki H, Barrett G, Halliday E, Halliday AM. Cortical potentials following voluntary and passive finger movements. Electroencephalogr Clin Neurophysiol 1980;50:201-13.

${ }^{33}$ Starr A, McKeen B, Skuse N, Burke D. Cerebral potentials evoked by muscle stretch in man. Brain $1981 ; 104: 149-66$.

${ }^{34}$ Vallbo AB. Muscle spindle afferent discharge from resting and contracting muscles in normal human subjects. In: Desmedt JE, ed. New Developments in Electromyography and Clinical Neurophysiology. Basel: Karger, 1973;vol. 3:251-62.

${ }^{35}$ Burke D, Hagbarth K-E, Lofstedt L. Muscle spindle activity in man during shortening and lengthening contractions. J Physiol (London) 1978;277:131-42.

${ }^{36}$ Soso MJ, Fetz EE. Responses of identified cells in postcentral cortex of awake monkeys during comparable active and passive joint movements. $J$ Neurophysiol 1980;43:1090-110.

37 Abrahamian HA, Allison T, Goff WR, Rosner BS. Effects of thiopental on human cerebral evoked responses. Anesthesiol 1963;24:650-7.

${ }^{38}$ Uttal WR, Cook L. Systematics of the evoked somatosensory cortical potential: a psychophysicalelectrophysiological comparison. Ann NY Acad Sci 1964;112:60-80.

${ }^{39}$ Bergamini L, Bergamasco B. Cortical evoked potentials in man. Springfield: Thomas, 1967:26-30.

${ }^{40}$ Stohr PE, Goldring S. Origin of somatosensory evoked scalp responses in man. $J$ Neurosurg 1969; 31:117-27.

41 Williamson PD, Goff WR, Allison T. Somato-sensory evoked responses in patients with unilateral cerebral lesions. Electroencephalogr Clin Neurophysiol 1970; 28:566-75.

42 Phillips CG. Motor apparatus of the baboon's hand. Proc roy Soc B 1969;173:141-74.

${ }^{43}$ Wiesendanger M, Ruegg DP, Lachat JM. The role of proprioceptive afferents in motor cortical output. In: Cobb WA, Van Duijin $\mathbf{H}$, eds. Contemporary Clinical Neurophysiology. Amsterdam: Elsevier, 1978:437-40.

44 Marsden CD, Merton PA, Morton HB. Servo action in the human thumb. $J$ Physiol (London) 1976;257: $1-44$.

${ }^{45}$ Paillard J, Brouchon M. A proprioceptive contribution to the spatial encoding of position clues for ballistic movements. Brain Res 1974;71:273-84.

${ }^{46}$ Angel RW. Antagonist muscle activity during rapid arm movements: central versus proprioceptive influences. J Neurol Neurosurg Psychiatry 1977;40: 683-6.

47 Dyhre-Poulsen P. Increased vibration threshold before movements in human subjects. Exper Neurol 1975; 47:516-22. 